\title{
BMJ Open Financial accessibility and user fee reforms for maternal healthcare in five sub-Saharan countries: a quasi-experimental analysis
}

\author{
Tiziana Leone, ${ }^{1}$ Valeria Cetorelli, ${ }^{1}$ Sarah Neal, ${ }^{2}$ Zoë Matthews ${ }^{2}$
}

To cite: Leone T, Cetorelli V, Neal S, et al. Financial accessibility and user fee reforms for maternal healthcare in five subSaharan countries: a quasi-experimental analysis. BMJ Open 2016;6:e009692. doi:10.1136/bmjopen-2015009692

- Prepublication history and additional material is available. To view please visit the journal (http://dx.doi.org/ 10.1136/bmjopen-2015009692).

Received 11 August 2015 Revised 23 October 2015 Accepted 17 November 2015

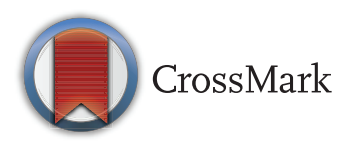

${ }^{1}$ Department of Social Policy, LSE, London, UK ${ }^{2}$ Department of Social Statistics, University of Southampton, Southampton, UK

Correspondence to Dr Tiziana Leone; t.leone@Ise.ac.uk

\section{ABSTRACT}

Objectives: Evidence on whether removing fees benefits the poorest is patchy and weak. The aim of this paper is to measure the impact of user fee reforms on the probability of giving birth in an institution or undergoing a caesarean section (CS) in Ghana, Burkina Faso, Zambia, Cameroon and Nigeria for the poorest strata of the population.

Setting: Women's experience of user fees in 5 African countries.

Primary and secondary outcome measures:

Using quasi-experimental regression analysis we tested the impact of user fee reforms on facilities' births and

CS differentiated by wealth, education and residence in Burkina Faso and Ghana. Mapping of the literature followed by key informant interviews are used to verify details of reform implementation and to confirm and support our countries' choice.

Participants: We analysed data from consecutive surveys in 5 countries: 2 case countries that experienced reforms (Ghana and Burkina Faso) by contrast with 3 that did not experience reforms (Zambia, Cameroon, Nigeria).

Results: User fee reforms are associated with a significant percentage of the increase in access to facility births (27 percentage points) and to a much lesser extent to CS (0.7 percentage points). Poor (but not the poorest), and non-educated women, and those in rural areas benefitted the most from the reforms. User fees reforms have had a higher impact in Burkina Faso compared with Ghana.

Conclusions: Findings show a clear positive impact on access when user fees are removed, but limited evidence for improved availability of CS for those most in need. More women from rural areas and from lower socioeconomic backgrounds give birth in health facilities after fee reform. Speed and quality of implementation might be the key reason behind the differences between the 2 case countries. This calls for more research into the impact of reforms on quality of care.

\section{INTRODUCTION}

In the last decade there has been growing political momentum to abolish user fees as a

\section{Strengths and limitations of this study}

- Using quasi-experimental statistical analysis and key informant interviews, this study analyses the impact of user fees removal in selected sub-Saharan countries on childbearing in facilities and on the likelihood of having a caesarean section controlling for key sociodemographic characteristics.

- The novelties and strengths of the study are that it analyses the impact of the reforms on the poorest and least educated. Furthermore, it combines econometrics with qualitative analysis to understand the impact of user fees removal for case study countries (Ghana and Burkina Faso) versus control countries (Zambia, Cameroon and Nigeria) where the fees have not been removed during the same period.

- A further strength of the study is that it used pseudo panel data from four successive Demographic and Health Surveys to analyse before and after effects. This allowed the analysis to be robust compared with previous studies.

- The limitation to this approach is that it was necessary to limit the number of countries included in the analysis because of the restrictions in the difference in difference modelling. In addition, a longer period after the last survey would have helped in understanding the full extent of the impact.

- This study is set within the international quest for universal health coverage in low-income countries.

strategy for increasing access to maternal and child health services. ${ }^{1-3}$ There is some indication that removal of user fees can contribute towards this objective from a recent systematic review $^{4}$ which concluded that there was some evidence to suggest that removal of user fees has increased the number of births at facilities, and may improve access to care for women with complications, although the quality of many of the studies included were poor. Probably the 
most robust evidence on the effect of user fees comes from a recent paper by McKinnon $e t a l^{5}$, which uses difference in difference modelling for a number of sub-Saharan African (SSA) countries: it confirms that removal of user fees is associated with an increase in the proportion of facility-based births, and a very small but significant reduction in the neonatal mortality rate.

However, along with many other studies, the analysis of McKinnon et a $\tilde{l}$ did not look at whether these reforms reach the poorest. Removal of user fees is often promoted as a pro-poor policy that will improve equity of access to care, but only a few studies are designed to investigate who benefits most. While there is some very limited evidence to suggest that removal of user fees can lead to increased uptake for the poor, ${ }^{6-8}$ it has emerged that the persistence of other financial and logistical barriers disproportionately affects the poorest, resulting in benefits from reforms being concentrated among richer women. ${ }^{9}$

The role of maternal education on the impact of user fee removal is also unclear: while we might expect the most educated to be the ones to take advantage of progressive reforms, it may also be expected that policies targeted to the hardest-to-reach populations would be taken up primarily by the least educated. Dzakpasu et $a l^{t}$ call for improved methods to analyse the relationship between user fees, education and access to services, and to consider issues of equity.

This study aims to establish the impact of user fees' reforms on access to facility births and caesarean sections (CS) in two sub-Saharan countries, Ghana and Burkina Faso, with particular focus on whether removal of user fees differentially benefits the poorest, whether there are inequalities by level of education, and whether it reaches equally across the population both in urban and rural areas. These two countries are compared with three others-Cameroon, Zambia, Nigeria-where user fees have not been reformed during the period considered, in order to compare effects. To the best of our knowledge it is the first study to look in-depth at the inequalities of the impact of user fees removal on maternal healthcare services. This research is timely, and is in line with the wider call for universal access to care, and in particular with the growing recognition of the importance of addressing inequities as essential to achieving overall progress in improving maternal health.

\section{DATA AND METHODS}

\section{Map of the evidence on user fees reforms in maternal and} child health

The process of selecting the countries had two phases: we first considered all SSA countries with a demographic and health surveys (Demographic and Health Survey; DHS): a total of 46 countries. We initially identified 21 countries in SSA with at least three DHS available within the last 20 years. This was done in order to use crosssectional data in a panel fashion and to be able to assess the impact of the reforms, including trends of births occurring in health facilities.

In the second phase, we comprehensively mapped the evidence though searches of government documents, peer review articles, and grey literature in these countries to ascertain whether any reforms had been carried out in the area of financing maternal and newborn healthcare. The search strategy included searching for terms related to maternal and child health reforms and user fees. We used main search engines as well as government and international websites for any documentation since 1990 to March 2014 (see online supplementary appendix). We found that nine had experienced a user fees removal reform in the area of maternal and child health $(\mathrm{MCH}), 11$ had fees in place and one had never had any fees in the last two decades. A summary of the selection strategy is reported in figure 1.

The countries selected were:

- Case study group: countries where the last survey was conducted at least 3 years after user fee removal/ reduction reforms: Burkina Faso introduced an $80 \%$ reduction in 2007, so while user fees were not totally abolished, a significant reduction was experienced. Ghana also experienced partial but progressive fee removals for institutional births from 2003 onwards with fees completely removed in April 2005.

- Control group: countries that did not have a universal exemption on user fees for institutional births during the study period (Cameroon, Zambia, Nigeria).

\section{Key informant interviews on user fees reforms in $\mathrm{MCH}$}

For each of the countries included in the analysis, we have interviewed at least one key expert based either in a relevant research-active university department, a Ministry of Health or relevant non-governmental organisation (NGO) to ascertain presence/absence of user fee reform history and its implementation. This is a particularly novel aspect of our study in that it recognises the importance of integrating qualitative information into the modelling in order to strengthen the choices made.

Two sets of open-ended structured questionnaires were devised, one for the control countries and one for the intervention ones. Ad hoc questions were introduced for each country to fill gaps in the existing literature. The content of the interviews was then used to fill gaps in the mapping of the literature and to ascertain whether the country selection was appropriate, as well as to get a clearer picture of the policy implementation. Informed consent was acquired from the interviewees, and ethical approval was received from the LSE ethics committee.

\section{Modelling impact of reforms \\ Country and outcomes selection}

In order to make the models as robust as possible, we reviewed findings from the evidence-mapping exercise and key informant interviews (KIIs) to consider the timeline of the reforms in each country and the concurrent availability of the survey data. We chose countries 


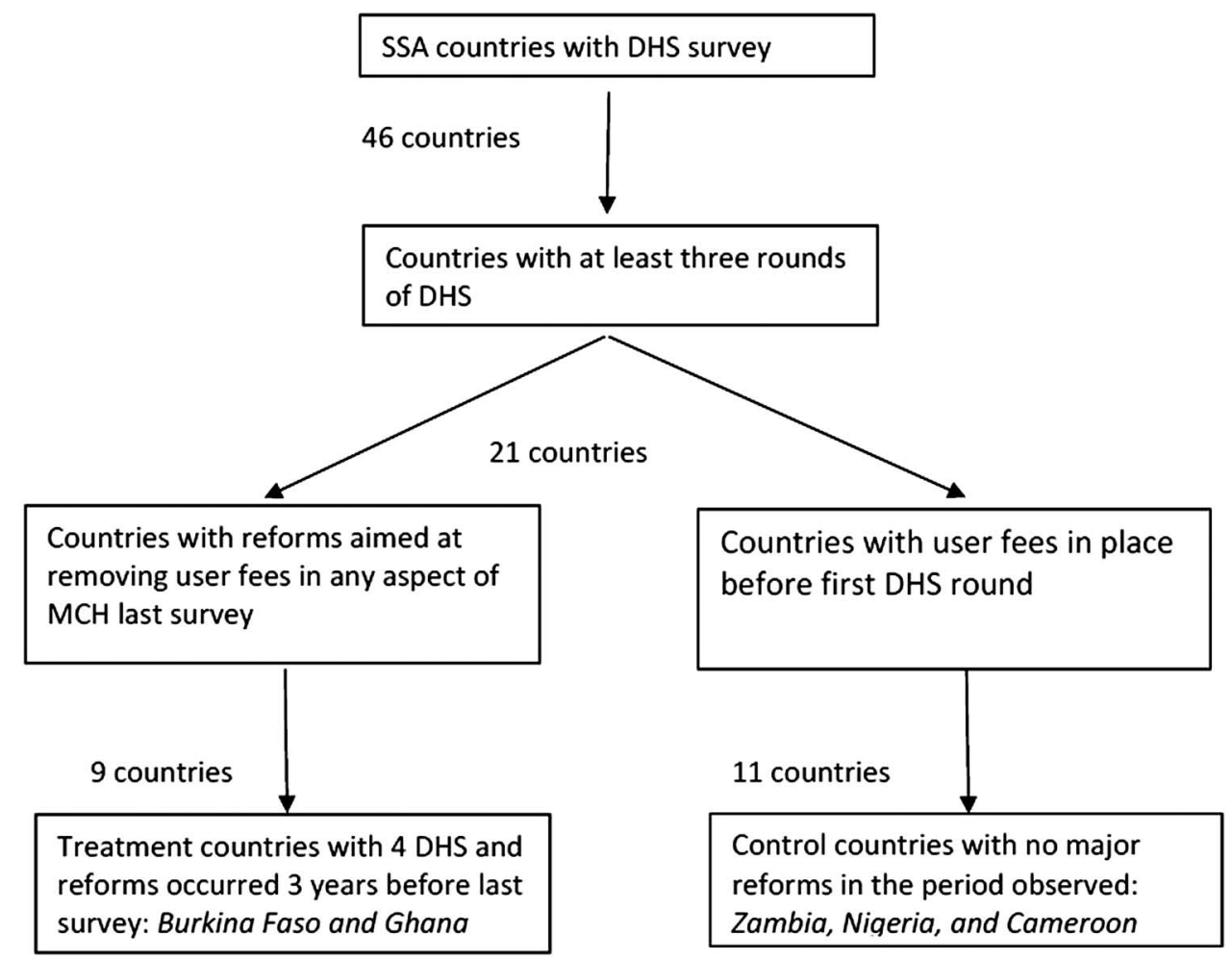

Figure 1 Country selection process. SSA, sub-Saharan African.

which showed similar trends of the indicators selected between the early 1990s and early 2000s across the countries considered whether case study or control.

In the 'treatment' group (the case study countries where reforms had been implemented to abolish user fees) we included only countries in which:

- The reform was initiated at least 3 years before the last survey in order to ensure that the policy had been fully implemented;

- At least four surveys were carried out (covering the early 1990s, late 1990s, early 2000s, late 2000s) to make the statistical analysis even more robust;

- At least three surveys were carried out before the reforms to establish trends in accordance with the hypothesis set by the difference in difference modelling as explained in the Methods section.

For the 'control' countries we used the following criteria:

- At least four DHS surveys have been carried out in the last 20 years;

- User fees are in place for MCH;

- No major health financing reform has been promulgated in the period under consideration.

Imposing these conditions ensured that the statistical modelling was as rigorous as possible. In particular, the use of four surveys as opposed to three as in McKinnon et $a l^{5}$ provides a more robust model, as we have more data to inform the pre-reform setting, therefore making sure any effects which do not relate to the user fees reforms are recognised. The use of four surveys creates pseudo cohorts which add further information to the study and make sure that the pre-reform trends are controlled for. However, it does also mean that we were more restricted in the number of countries we could choose, and made the selection process more cumbersome. Nevertheless, this further strengthens the difference in difference assumption that the pre-policy trends should be similar in all control and case countries.

The analysis focused on facility births and CS rates. Care at birth in facilities has long been considered as a key indicator for assessing progress in maternal and child healthcare. ${ }^{10}$ Very low levels of caesarean birth (eg, below 5\%) is recognised as a key indicator of lack of access to life-saving emergency care and often used as a proxy for poor quality of care/lack of access to care in the absence of appropriate data. ${ }^{10}$ A total of 187310 women were included in the analysis.

\section{Statistical analysis}

The effect of user fee removal on maternal health outcomes was identified using a difference-in-difference approach. ${ }^{11}$ We compared trends in maternal health from the early 1990s to the late 2000s in two countries where user fees were recently removed or drastically reduced (Burkina Faso and Ghana), with trends in three countries which did not experience any healthcare reform over the entire study period (Cameroon, Nigeria and Zambia). The underlying assumption is that, in the absence of user fee reforms, maternal health outcomes in Ghana and Burkina Faso would have been affected by other time-varying factors in the same way as maternal health outcomes in Cameroon, Nigeria and Zambia. 
We then estimated separate models by women's educational level, wealth quintiles and residence, to quantify the effect of user fees reforms on maternal health equity. While the general model estimates the average effect of user fee removal across all women, these disaggregated models make it possible to evaluate whether the effect of user fee removal varies across educational and wealth groups, and to identify what groups benefit the most from it. We also want to see whether education might have a stronger effect than wealth, or vice versa, or simply behaving similarly. No other study has done this to date.

Control factors are age of the woman, parity, country, period (survey), education and wealth calculated separately for urban and rural areas to account for the different weighting of asset indicators. This is a further strength of this study which makes the results of the differential analysis more robust.

\section{RESULTS}

\section{Key informant interviews}

The KIIs confirmed the findings of a number of previous studies, in particular, they highlighted the lack of clarity surrounding user fee policy implementation of the abolition of the user fees. In particular, both KIIs for Ghana and Burkina Faso stressed the struggle to implement the reforms once they were issued.

In Burkina Faso, the implementation of user fees was launched in 1993 as part of the Bamako Initiative. ${ }^{12}$ Part of the implementation policy included exemptions that required the state to cover user fees for the indigent. Even so, Burkina Faso is one of the countries interested by the phenomenon of the implementation gap. User fees for maternal services were completely removed in 2002 for antenatal care (ANC), later in 2007, an 80\% reduction in fees was applied for childbirth, and in 2006 for CS. ${ }^{13}{ }^{14}$ A transparent fees structure was launched such that fixed fees were charged depending on whether they were uncomplicated or complicated CS. Free transportation was also offered for emergency CS from district health centres to regional facilities. The 'worse off' (defined as the $20 \%$ of the poorest in the country) were expected to be able to access these services for free, and according to the KII, they did indeed access the services making Burkina Faso a strong case selection for our study. However, as the KII stressed, reforms were not implemented uniformly as there was low awareness of this opportunity among service providers and users. Finally the $20 \%$ is still a considerable financial barrier for many women which is not negligible when considering the impact of the reforms.

In Ghana, fees were in place since 1967, with major increases between 1983 and 1985. A series of exemptions for target parts of the population (low income, $\mathrm{MCH}$ ) is in use, but previous studies have showed that these exemptions are often not applied, or illegal fees are charged by individual hospitals. The user fee exemption was enacted in 2003 when user fees were removed in four of the poorest regions. In April 2005, this was rolled out fully to the rest of the country. However, this was not implemented uniformly and funding was inconsistent as some facilities subsequently reintroduced user fees and there was 'general erosion of confidence in the health system'. ${ }^{15}$ Many criticise the speed at which these exemptions were introduced generating a lack of funds followed by a fall in quality. ${ }^{6} 16$ A National Health Insurance Scheme (NHIS) was implemented in 2005 consisting of free ANC, childbirth, postnatal and neonatal care. However, an independent evaluation found that the scheme did not have the effect of increasing access. ${ }^{15}$ In addition, it might have marred the impact of user fees removal as some of the fees crept up again and made the reforms less effective up to the point when the NHIS was given free to all pregnant women. In effect, the national insurance did not have an impact during the period of observation of this study.

We used Zambia as a control country, as while it removed user fees in 2006 in rural areas only, this occurred after the last DHS survey was conducted. ${ }^{3} 17$ Currently, fees are payable (by cash) in urban areas. A nominal fee of $\$ 1$ for MCH though deliveries, CS, ANCs are free. According to the KII, fees have been a barrier holding back the institutional birth rate that was the aim of the reforms. In urban areas, keeping nominal fees lowered institutional births and scheduled ANCs. The KII also stressed that although Zambia experienced user fee reforms at the time of the 2007 survey, they had not been implemented properly and no impact had been seen in the following year or two, making it a perfect control country, as the trends also confirmed. In addition, despite the 2013/2014 survey being recently released, Zambia could still not be considered as a case study released. This is because of the period under observation in this study which stops at the end of the 2000s. Once more, surveys are added, and a fuller new analysis can be conducted where Zambia can be used as a case study.

In Nigeria, there has been no clear federal policy on user fees in maternal and child health, and the regional variation at primary and secondary level is vast. ${ }^{18}$ Since 2006, ANC user fee exemption has been piloted in a few regions, but so far no record has been made of more systematic approaches to the fees scheme. Furthermore, it was of small scale and in primary facilities only.

Finally, user fees were introduced in Cameroon in 1992. A study published immediately after the reform showed that the poorest quartile of the population, more susceptible to the cost of health services. ${ }^{19}$ No exemption has been given for MCH services. In the view of the KII, there is an issue of affordability for most of the women below the poverty line. However, the public perception is that the fees maintain quality of care. Transportation and distance are also issues contributing to a low level of facility births. 
Impact of removing user fees for births in facilities and CS Figures 2 and 3 show the trends in the proportion of women who give birth in a facility, CS rates and birth facilities for the lowest two quintiles. It is noticeable in figure 2 that there is an increase, postreform, in access to facility births in the case countries. From the early 1990s until the early 2000s, that is, before any healthcare reform, percentages remained relatively stable in all countries. After user fee reforms in Burkina Faso and Ghana, women giving birth in health facilities increased from $40 \%$ to $70 \%$, and from $45 \%$ to $60 \%$, respectively. Interestingly, almost all countries saw decreases until around 2000, and then all experienced increases with the exception of Nigeria.

The findings suggest user fees' reforms account for up to 25 percentage points of the increase in access to institutional deliveries (table 1). Access increased with increasing education and wealth as well as with age. The impact on CS ( 0.7 percentage points overall increase in the period under observation due to the fee exemption reforms) was not as strong as the effect for institutional deliveries.

Overall, the results show a higher increase in childbearing in health facilities for Burkina Faso rather than Ghana. The odds of having a facility birth increases with increasing education attainment across all countries in the study, and likewise for the odds of obtaining a CS. Wealth is not a significant effect when controlling for other factors in the facility birth model, while it increases significantly for CS as the level of wealth goes up showing wealthier women having more access to CS. Low levels of education and average wealth do seem to have reported the highest benefit in accessing institutional births. Thus, the opposite relationship is true for CS where the risk increases significantly with wealth as expected.

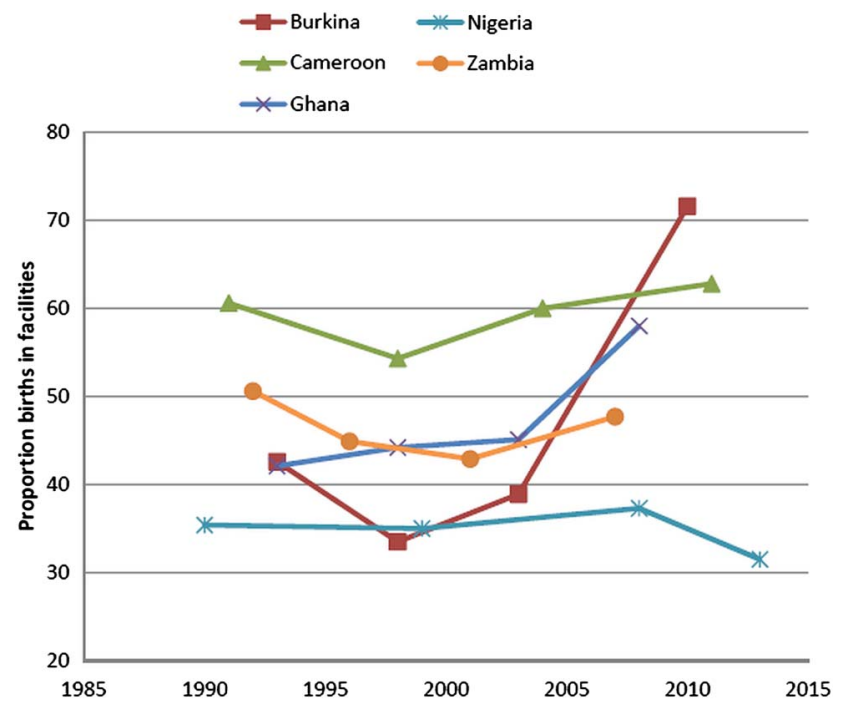

Figure 2 Trends in the proportion of births in facilities 19902011 during period of user fee reform in all countries (exemption on user fee reforms: Ghana-2005 and Burkina Faso-2006).

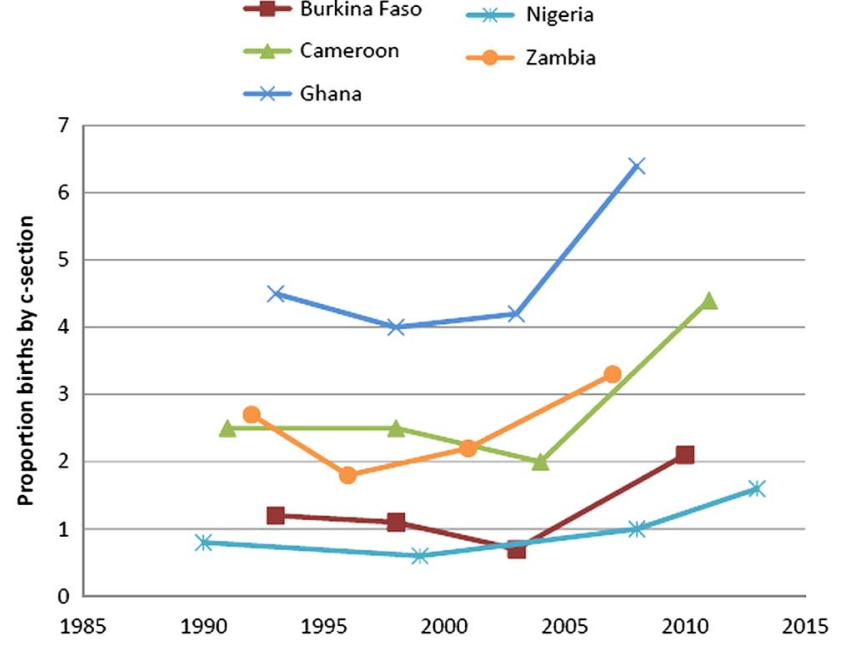

Figure 3 Trends in the proportion of births by caesarean section 1990-2013 during period of user fee reform in all countries (exemption on user fee reforms: Ghana-2005 and Burkina Faso-2006).

Table 2 shows that births in facilities increase as educational level decreases. There is also clear gradient of births in facilities by wealth, with the greatest impact seen among the poor. CS show the opposite: removal of user fees has the greatest impact on those of aboveaverage wealth (although again it was not significant for the richest). Last rural areas clearly benefit most from removal of fees with an increase of over 30 percentage points of the increase of facility births which can be attributed to the removal of user fees compared to 6 percentage points in urban areas. Similar patterns were found for CS.

\section{Discussion and conclusions}

Two key messages emerge from this study: there is a significant impact of the user fees' reforms on childbearing in health facilities in the two countries considered, and the implementation did not have an equal impact across socioeconomic groups. More specifically, the differential analysis for institutional deliveries shows that the non-educated and poorer groups (below average and average quintiles) were the ones to benefit the most. Furthermore, rural areas seem to have fared best because of the reforms. However, those in the poorest quintile still do not seem to be the ones who have had the greatest improvement.

A further key message of this study is that the models show that while the user fees removal did have a strong impact on increasing institutional deliveries, CS did not benefit greatly. Quality of care might still be an issue despite managing to get women into the hospitals mainly given the low levels of CS in the countries studied. This study calls for more measures of quality of care to be tested.

Illiterate women are those who benefit most from greater access to institutional delivery but this is not 
Table 1 Determinants of level of facility births, caesarean sections using difference in difference modelling in five sub-Saharan African countries to test user fees policy removal (adjusted for other fixed effects)

\begin{tabular}{|c|c|c|c|c|}
\hline & $\begin{array}{l}\text { Birth in facilities } \\
\text { Coefficients/SE }\end{array}$ & p Value & $\begin{array}{l}\text { Caesarean section } \\
\text { Coefficients/SE }\end{array}$ & p Value \\
\hline No fees & $0.248(0.006)$ & 0.000 & $0.007(0.002)$ & 0.001 \\
\hline \multicolumn{5}{|l|}{ Country } \\
\hline Burkina Faso & Ref & & & \\
\hline Cameroon & $0.0117(0.005)$ & 0.025 & $0.010(0.002)$ & 0.000 \\
\hline Ghana & $-0.164(0.006)$ & 0.000 & $0.021(0.002)$ & 0.000 \\
\hline Nigeria & $-0.202(0.005)$ & 0.000 & $0.009(0.002)$ & 0.576 \\
\hline Zambia & $-0.148(0.005)$ & 0.000 & $0.007(0.002)$ & 0.002 \\
\hline \multicolumn{5}{|c|}{ Period (ref second half 2000s) } \\
\hline First half of 1990 s & $-0.044(0.005)$ & 0.000 & $-0.0047(0.001)$ & 0.011 \\
\hline Second half of 1990 s & $-0.0326(0.004)$ & 0.000 & $-0.010(0.001)$ & 0.000 \\
\hline First half of 2000s & $-0.0178(0.0042)$ & 0.000 & $-0.002(0.002)$ & 0.013 \\
\hline \multicolumn{5}{|l|}{ Education (ref none) } \\
\hline Primary & $0.204(0.004)$ & 0.000 & $0.006(0.001)$ & 0.000 \\
\hline Secondary+ & $0.327(0.004)$ & 0.000 & $0.023(0.002)$ & 0.000 \\
\hline \multicolumn{5}{|l|}{ Age (15-19 ref) } \\
\hline $20-24$ & $0.0205(0.006)$ & 0.000 & $0.006(0.002)$ & 0.013 \\
\hline $25-29$ & $0.0678(0.006)$ & 0.000 & $0.019(0.002)$ & 0.000 \\
\hline $30-34$ & $0.091(0.007)$ & 0.000 & $0.031(0.003)$ & 0.000 \\
\hline $35-39$ & $0.106(0.007)$ & 0.000 & $0.041(0.003)$ & 0.000 \\
\hline $40-44$ & $0.117(0.008)$ & 0.000 & $0.044(0.003)$ & 0.000 \\
\hline $45-49$ & $0.107(0.010)$ & 0.000 & $0.043(0.004)$ & 0.000 \\
\hline \multicolumn{5}{|l|}{ Residence (rural ref) } \\
\hline Urban & $0.159(0.004)$ & 0.000 & $0.011(0.002)$ & 0.000 \\
\hline \multicolumn{5}{|l|}{ Children ever born (1 ref) } \\
\hline 2 & $0.0715(0.004)$ & 0.000 & $-0.016(0.002)$ & 0.000 \\
\hline $3+$ & $-0.125(0.005)$ & 0.000 & $-0.032(0.002)$ & 0.000 \\
\hline \multicolumn{5}{|c|}{ Wealth quintile (poorest ref) } \\
\hline Poor & $0.043(0.004)$ & 0.000 & $0.001(0.001)$ & 0.443 \\
\hline Average & $0.1255(0.004)$ & 0.000 & $0.005(0.001)$ & 0.000 \\
\hline Rich & $0.239(0.005)$ & 0.000 & $0.010(0.002)$ & 0.000 \\
\hline Richest & $0.322(0.006)$ & 0.000 & $0.031(0.003)$ & 0.000 \\
\hline Constant & $0.289(0.007)$ & 0.000 & $0.008(0.002)$ & 0.002 \\
\hline
\end{tabular}

reflected in our findings on CS. Our findings also raise issues as to why poorer groups showed greater access to institutional care than the poorest. In addition, our study raises the issue on whether urban areas might have been neglected in the implementation of the reforms to increase access in the rural and more disadvantaged areas.

In addition, the study shows a clear better result on the increase in institutional deliveries after the removal of user fees for Burkina Faso rather than Ghana. In this respect, the KII interviews were a key advantage of this study, and gave a stronger understanding of context than is normally found in studies using statistical analysis of secondary data.

Both countries undoubtedly faced challenges while implementing the policy, and limitations were identified in the way the policy was designed and planned, particularly around financing. Ghana, however, suffered from particularly acute and severe problems with funding, which was in many regions inadequate and unpredictable. This was partly as a result of decisions made at central government level where Allocation of Heavily Indebted Poor Countries funding to the health sector was reduced. In some regions, funds ran out, resulting in the reintroduction of user fees. ${ }^{20}$

While problems were also documented around implementation in Burkina Faso, a comparison of six countries suggests that Burkina Faso performed better at implementing the reforms than Ghana in a number of areas including technical leadership by the Ministry of Health, capacity building and the degree to which new rules were followed by different actors. ${ }^{21}$ There is some evidence that the policy in Burkina Faso reduced out-of-pocket expenses and did not have an adverse effect on quality. ${ }^{22}{ }^{23}$ A further interesting point why uptake may have been greater in Burkina Faso was because the fee set for normal deliveries was significantly higher than the real cost. As highlighted in our interviews, the guidelines on how this money should be allocated were not clear, and in particular what proportion could be claimed by staff as bonuses. This led to some health centres developing practices which may 
Table 2 Effect of user fees removal in Ghana and Burkina Faso on the probability of institutional delivery by women's education, household wealth and residence

\begin{tabular}{|c|c|c|c|c|}
\hline & \multicolumn{2}{|c|}{ Facility births } & \multicolumn{2}{|c|}{ Caesarean section } \\
\hline & Coefficient & $\begin{array}{l}\mathbf{p} \\
\text { Value }\end{array}$ & Coefficient & $\begin{array}{l}\mathbf{p} \\
\text { Value }\end{array}$ \\
\hline \multicolumn{5}{|l|}{ Education } \\
\hline $\begin{array}{l}\text { No } \\
\text { education }\end{array}$ & 0.310 & 0.000 & 0.011 & 0.000 \\
\hline Primary & 0.160 & 0.000 & 0.012 & 0.017 \\
\hline $\begin{array}{l}\text { Secondary } \\
\text { or higher }\end{array}$ & 0.060 & 0.000 & 0.005 & 0.568 \\
\hline \multicolumn{5}{|l|}{ Wealth } \\
\hline Poorest & 0.240 & 0.000 & 0.007 & 0.025 \\
\hline $\begin{array}{l}\text { Below } \\
\text { average }\end{array}$ & 0.340 & 0.000 & 0.010 & 0.004 \\
\hline Average & 0.330 & 0.000 & 0.011 & 0.013 \\
\hline $\begin{array}{l}\text { Above } \\
\text { average }\end{array}$ & 0.250 & 0.000 & 0.015 & 0.014 \\
\hline $\begin{array}{l}\text { Richest } \\
\text { Residence }\end{array}$ & 0.010 & 0.551 & -0.013 & 0.143 \\
\hline Rural & 0.315 & 0.000 & 0.049 & 0.007 \\
\hline Urban & 0.061 & 0.000 & 0.011 & 0.000 \\
\hline
\end{tabular}

have provided strong incentives to staff to increase deliveries. ${ }^{21}$

This study has a number of limitations. The time lag is quite short between the introduction of some of the reforms and the survey date. In particular, given delays in implementing policies nationwide, we might have missed the full impact of the reforms. Ideally, to get a more representative picture of the African settings we should have included more countries in the analysis. However, we believe that by keeping strict inclusion rules we have made the application of the difference in difference approach more robust than that done by McKinnon et $a .^{5}$ Furthermore, the bigger number of data sets included for each country (four in our analysis as opposed to three) allows us to have a stronger idea of the pre-reform period and control for other externalities. In addition, there could potentially be the effect of competing reforms implemented at the same time and which we might have missed. However, we think we have addressed this in our analysis through confirming during the qualitative interviews that no additional financial or structural reforms were implemented during the period when the user fees were removed, which we had accounted for in the models. For this reason, the timing of surveys along with the time covariate which was used in the model further add to the robustness of the results. Last but not least, ideally we would have wanted to test the speed of implementation as well, but a greater number of case study countries would have needed to be analysed. While evidence increases that removing user fees creates a benefit for women to access services it is also undeniable that rapid abolition without careful planning can cause harm at least in the short term. However, this was beyond the scope of this study, and these issues are looked at elsewhere. $^{12425}$

The health systems implications of removal on user fees (on financing, relating to higher demand for commodities, increased workload for human resources), and strategies to optimise the chances of success of user fees removal $^{25-27}$ need to be further investigated. Despite improved access, including for the poor, financial barriers still exist, and user fees may still be reinstated as the argument that they improve services, although unsubstantiated, is still widely articulated. ${ }^{22}$ Increased public financing in particular is needed to improve quality of care and availability of services, and to make up for the decrease in funding. The small impact of the user fees reforms shown in the results of the CS models is partly due governments failing to identify a replacement for user fees incomes in the health system.

User fees have been shown to have failed on many levels in previous research, and the evidence is now growing on the benefits of removing fees. Despite the warnings put in place in the last decade it is clear also in light of our review, that removing user fees are benefitting the poor. The lessons learned from the Ghanaian and Burkina Faso experiences are that clear leadership and ownership of the reforms as well as a sustained and well-planned implementation are key in moving forward. Future research will need to look more in depth into the stages of the reforms as well as into the pace of the implementation. It is important to carry out more research like this on the implementation of financing reforms to really understand the impact of user fee introduction and removal. This would include its unintended consequences should the health system not be prepared to respond to any increased demand. Ultimately, these lessons learned will contribute further to help those countries considering a move towards universal healthcare.

Twitter Follow Tiziana Leone at @tizianaleone

Acknowledgements We would like to thank the members of the Countdown to 2015 Health Policy and Systems group for their valuable feedback in particular Jennifer Requejo, Joy Lawn and Neha Sigh. We thank Giulia Gabrielli for the thorough review of the literature.

Contributors TL set up the research questions, the analysis, the KII interviews and wrote the first draft of the paper. VC run the analysis and contributed to the drafting of the paper. SN contributed to the methodology and policy analysis. ZM contributed to the objectives, policy analysis and drafting of the paper.

Funding This work was funded through a subgrant from the U.S. Fund for UNICEF under their Countdown to 2015 for Maternal, Newborn and Child Survival Grant (\#0PP1058954) from the Bill and Melinda Gates Foundation.

Competing interests None declared.

Ethics approval London School of Economics Ethical Committee.

Provenance and peer review Not commissioned; externally peer reviewed. Data sharing statement No additional data are available. 
Open Access This is an Open Access article distributed in accordance with the Creative Commons Attribution Non Commercial (CC BY-NC 4.0) license, which permits others to distribute, remix, adapt, build upon this work noncommercially, and license their derivative works on different terms, provided the original work is properly cited and the use is non-commercial. See: http:// creativecommons.org/licenses/by-nc/4.0/

\section{REFERENCES}

1. Borghi J, Ensor T, Somanathan A, et al. Mobilising financial resources for maternal health. Lancet 2006;368:1457-65.

2. Lagarde M, Palmer N. The impact of user fees on access to health services in low- and middle-income countries. Cochrane Database Sys Rev 2011;(4):CD009094.

3. Yates R. Universal health care and the removal of user fees. Lancet 2009;373:2078-81.

4. Dzakpasu S, Powell-Jackson T, Campbell OM. Impact of user fees on maternal health service utilization and related health outcomes: a systematic review. Health Policy Plan 2014;29:137-50.

5. McKinnon B, Harper S, Kaufman JS, et al. Removing user fees for facility-based delivery services: a difference-in-differences evaluation from ten sub-Saharan African countries. Health Policy and Planning 2015;30:432-41.

6. Penfold S, Harrison E, Bell J, et al. Evaluation of the delivery fee exemption policy in Ghana: population estimates of changes in delivery service utilization in two regions. Ghana Med $J$ 2007:41:100-9.

7. Xu K, Evans DB, Kadama P, et al. Understanding the impact of eliminating user fees: utilization and catastrophic health expenditures in Uganda. Soc Sci Med 2006;62:866-76.

8. Deininger K, Mpuga P. Economic and welfare impact of the abolition of health user fees: evidence from Uganda. $J$ Afr Econ 2005;14:55-91.

9. El-Khoury M, Hatt L, Gandaho T. User fee exemptions and equity in access to caesarean sections: an analysis of patient survey data in Mali. Int J Equity Health 2012;11:49.

10. WHO. The World Health Report 2005: make every mother and child count. Geneva: WHO, 2005

11. Angrist J, Pischke DJ-S. Mostly Harmless Econometrics: an Empiricist's Companion. Princeton University Press, 2009.

12. Ridde V. Fees-for-services, cost recovery, and equity in a district of Burkina Faso operating the Bamako Initiative. Bull World Health Organ 2003;81:532-8.
13. Ridde V, Morestin F. A scoping review of the literature on the abolition of user fees in health care services in Africa. Health Policy Plan 2011;26:1-11

14. Ridde V, Richard F, Bicaba A, et al. The national subsidy for deliveries and emergency obstetric care in Burkina Faso. Health Policy Plan 2011;26(Suppl 2):ii30-40.

15. Hera. Evaluation of the Free Maternal Health Care Initiative in Ghana. HERA. Accra, Ghana \& Reet, Belgium. 2013

16. Mensah J, Oppong JR, Schmidt CM. Ghana's national health insurance scheme in the context of the health MDGs: an empirical evaluation using propensity score matching. Health Econ 2010;19 (Supp1):95-106.

17. Witter S. Mapping user fees for health care in high-mortality countries: evidence from a recent survey. HSLP Institute working paper. London, 2010.

18. Okonofua F, Lambo E, Okeibunor J, et al. Advocacy for free maternal and child health care in Nigeria-Results and outcomes. Health Policy 2011;99:131-8.

19. Litvack JI. User fees plus quality equals improved access to health care: results of a field experiment in Cameroon. Social Science \& Medicine 1993;37:369.

20. Witter S, Arhinful DK, Kusi A, et al. The experience of Ghana in implementing a user fee exemption policy to provide free delivery care. Reprod Health Matters 2007;15:61-71.

21. Meessen $B$, Hercot $D$, Noirhomme $M$, et al. Removing user fees in the health sector: a review of policy processes in six sub-Saharan African countries. Health Policy Plan 2011;26(Suppl 2):ii16-29.

22. Ridde V, Agier I, Jahn A, et al. The impact of user fee removal policies on household out-of-pocket spending: evidence against the inverse equity hypothesis from a population based study in Burkina Faso. Eur J Health Econ 2015;16:55-64.

23. Ridde V, Queuille L, Kafando Y, et al. Transversal analysis of public policies on user fees exemptions in six West African countries. BMC Health Serv Res 2012;12:409.

24. James $\mathrm{C}$, Hanson $\mathrm{K}$, McPake B, et al. To retain or remove user fees? Appl Health Econ Health Policy 2006;5:137-53.

25. McPake B. User charges for health services in developing countries: a review of the economic literature. Soc Sci Med 1993;36:1397-405.

26. Gilson L. The lessons of user fee experience in Africa. Health Policy Plan 1997:12:273-85.

27. Gilson L, Mills A. Health sector reforms in sub-Saharan Africa: lessons of the last 10 years. Health Policy 1995;32:215-43.

28. McPake B, Hanson K, Mills A. Community financing of health care in Africa: an evaluation of the Bamako initiative. Soc Sci Med 1993;36:1383-95. 